Article

\title{
Job Insecurity and Employee Engagement: A Moderated Dual Path Model
}

\author{
Shengxian $\mathrm{Yu}^{1}{ }^{1}$, Xiaoxiao Gong ${ }^{2}$ and $\mathrm{Na} \mathrm{Wu}^{3, *}$ \\ 1 School of Business Administration, South China University of Technology, Guangzhou 510640, China; \\ yushengxian1012@126.com \\ 2 School of Business Administration, Southwestern University of Finance and Economics, \\ Chengdu 611130, China; gxx@smail.swufe.edu.cn \\ 3 School of Business Administration, Zhongnan University of Economics and Law, Wuhan 430000, China \\ * Correspondence: 201801080042@stu.zuel.edu.cn
}

Received: 16 November 2020; Accepted: 30 November 2020; Published: 3 December 2020

check for updates
updater

\begin{abstract}
In a new stage of booming platform economy, improving the employees' job security is the key factor to ensure the sustainable development of a platform organization. Based on the cognitive behavior theory, this study introduces the perceived insider status as the moderator variable, and constructs the process mechanism model of job insecurity on employee engagement. The aim of this study is to examine the relationship between job insecurity, emotional response and employee engagement, and provide suggestions for reducing job insecurity and improving employee engagement. Using a 2-wave time-lagged survey data of 341 workers in China firms, data were collected with a self-report questionnaire and analyzed with the statistical package for the social science (AMOS, SPSS). The research result found a negative relationship between job insecurity and employee engagement, and that this negative relationship was mediated by negative emotion or positive emotion. Furthermore, perceived insider status moderated the relationship between job insecurity and positive emotion or negative emotion; the higher the perceived insider status is, the weaker the negative impact of job insecurity on positive emotion and the weaker the positive impact on negative emotion. The research results provide theoretical guidance for organizations to improve employee engagement and help to strengthen the importance of organizations to employees' job insecurity.
\end{abstract}

Keywords: job insecurity; employee engagement; negative emotion; positive emotion; perceived insider status

\section{Introduction}

With the rise of the digital platform economy and the reform of state-owned enterprises and institutions, the traditional employment mode of "iron rice bowl" has undergone a fundamental reversal, and new flexible employment forms with labels such as "temporary", "mobile" and "insecure" have gradually dominated the employment stage. The changing working environment makes employees feel more insecure than ever before, and job insecurity has become one of the most common workplace psychological problems faced by employees [1]. Job insecurity is defined as a subjective and unconscious perception of job loss; to put this another way, job insecurity can be described as employees' recognition of a threat from any changes in the job environment [1], including the fear of losing the job itself and the threat of losing the job's benefits and characteristics (such as salary, position, etc.) [2]. A large number of studies have shown that job insecurity has become a common source of stress for employees. On the one hand, negative workplace effects caused by job insecurity, such as turnover intention [3], workplace silence [4], workplace bullying [5], etc., that will undermine 
the organization's human resource management system, thus affecting the sustainable development of the organization. On the other hand, employees' mental health problems caused by job insecurity, such as emotional exhaustion [6], anxiety [7], etc., that will destroy the family harmony of employees, lead to a decline in health and quality of life, and have an impact on social stability and sustainable development [8]. Therefore, job insecurity issues are critical to the sustainability of organizations and societies. But the current research on job insecurity is mostly based on the background of western countries, however there are significant differences between Chinese and Western cultures, especially as China is in a transition stage, with a higher culture of uncertainty and a more prosperous online economy, and job insecurity may be more seriously affected in China. Therefore, it is of great practical significance to study job insecurity in the context of China. Our research will explore the mechanism of job insecurity from three aspects: First, employee engagement is selected as the outcome variable. As a state where individuals are fully engaged in their job roles, employee engagement has always been a hot issue of human resource management, including the degree of individual resource investment in emotion, intelligence, and physical strength [9]. The choice of engagement as a result variable is based on two considerations. First, employee engagement has become a bottleneck restricting the sustainable development of Chinese enterprises. According to the 2011 engagement survey report released by The American Callup Research Company, employee engagement is only 6\% in Chinese enterprises, far lower than the proportion of engaged employees in the world. "go on tolling the bell as long as one is a monk" is a common phenomenon [10]. Employee engagement level not only has an important impact on job engagement, job performance, organizational performance, etc. [11,12], but also causes employees' deviant behavior, emotional exhaustion, employee demission, etc. [10]. Obviously, individual engagement level has special significance for improving organizational efficiency and ensuring sustainable development [13]. Therefore, under the changeable working environment, how to improve employee engagement to ensure the sustainable development of the organization has become an urgent problem to be solved. Furthermore, the impact of job insecurity on employee engagement is controversial. Most researchers believe that job insecurity will have a negative impact from the perspective of hindrance. For example, some studies believe that job insecurity has a significant negative impact on employee engagement, and job insecurity reduces employees' participation and initiative in their work [14]. From a challenging perspective, some studies believe that job insecurity has a positive impact on engagement. For example, some scholars found job insecurity has a significant positive impact on engagement by a large number of interviews and surveys $[15,16]$. Therefore, the impact of job insecurity on employee engagement needs to be further verified. Secondly, positive and negative emotions are introduced into the research framework as mediating variables. Although previous studies have explored the relationship between job insecurity and employee engagement, it is worth noting that most studies only examine the direct impact of job insecurity on the engagement. Additionally, according to cognitive behavior theory (emotional ABC theory), emotion plays a mediating role between individual cognition and behavior. After individual cognition is stimulated by the environment, emotion will be generated, and then affect employees' behavioral choice. [17]. So, let us consider: how does job insecurity affect employee engagement through different emotional pathways? Cognitive behavioral theory provides us with an explanatory perspective. As an important perception, job insecurity is also influenced by emotions. At the same time, with emotion as a kind of emotional resource, emotional state will directly affect the choice of individual behavior strategy. Positive emotions can produce a positive behavior motivation, such as organizational citizenship behavior [18], altruistic behavior [16], etc. Negative emotions will lead to negative behavior choice, such as the production behavior and silence behavior $[19,20]$, etc. It will directly affect the sustainable development of the organization. Finally, this study takes perceived insider identity as the boundary condition. Based on the values of collectivism, China has always guided individual collaboration with collective consciousness to achieve the goal. In this cultural context, whether employees have a strong sense of organizational belonging and goal identification, and perceive their internal organizational membership, will directly affect their performance at work [21]. Therefore, perceived insider identity, 
as an important dimension of self-concept, has gradually become a measurement index in organizational behavior research. The higher the perceived insider identity is, the more obvious the positive effect will be and the higher the degree of effort will be [22]. Based on this, this study, using the cognitive behavior theory, attempts to construct the internal mechanism of action between job insecurity and employee engagement through emotional expression, and studies the moderating effect of perceived insider identity on this mediating effect.

\section{Literature Review and Hypothesis Development}

\subsection{Job Insecurity and Employee Engagement}

Job insecurity, as a source of stress, comes from two aspects: one is the perception of the risk of losing the current job, the other is the worry of losing or changing the job characteristics [23]. Existing research conclusions on the outcome effects of job insecurity can be divided into two categories. First, it is believed that working time pressure, as a source of obstructive stress, has negative effects on job engagement, organizational commitment, happiness, etc. $[3,24,25]$. The second suggests that job insecurity can be seen as a source of challenging stress, which has a positive effect on individual experience. For example, job insecurity can stimulate employees' enthusiasm and creativity and improve their work performance [26-28]. Therefore, scholars' conclusions on the effects of job insecurity are still controversial, and as such, the impact of job insecurity should be analyzed on a case-by-case basis.

According to the cognitive behavioral theory, job insecurity can easily trigger individuals' negative response, which can be elaborated from three aspects. First of all, when experiencing job insecurity, employees usually think that it is meaningless to consume resources to cope with the pressure of insecurity, there is no intrinsic motivation to deal with job insecurity. At this time, employees are likely to deal with job insecurity through negative ways such as job withdrawal or engagement reduction [29]. In addition, based on the resource conservation theory, some researchers found that due to the limitation of internal resources, individuals usually lack sufficient energy and resources to cope with external pressure, resulting in reduced engagement [30]. Employment as a demand, when employees are aware that their work is in a dangerous state (that is, a high degree of job insecurity), that is, their needs are threatened or cannot be met, individuals tend to protect their own resources and reduce the input of work resources [4]. Secondly, job insecurity can induce individuals to produce emotions such as anxiety, complaint and depression, and these adverse emotional reactions will lead to deviant behaviors to varying degrees. Researchers show that through meta-analysis of work insecurity, emotional exhaustion caused by job insecurity would lead to the decrease in employees' job involvement. Compared with job involvement, employee engagement, as a more sensitive indicator of work attitude, may have a more serious impact on job engagement [31]. Finally, job insecurity increases employees' perception and concern about the loss of important job characteristics. Studies have pointed out that organizational management behaviors not only affect employees' sense of identity, but also affect their attitudes and behaviors. Employees evaluate the value of their own efforts and contributions by judging the behavior of managers [32]. Kahn pointed out that the sense of work meaning from job characteristics would motivate individuals to better put themselves into their work [33]. Saks, through the perspective of social exchange theory, analyzed the antecedent and outcome variables of employee engagement; the results showed that job characteristics are significantly related to employee engagement [34]. Therefore, this study concluded that job insecurity, as a significant job characteristic, was closely related to employee engagement. Based on the above analysis, this study proposes the following hypotheses:

Hypothesis 1. Work insecurity has a significant negative impact on employee engagement. 


\subsection{The Mediating Effect of Positive and Negative Emotions}

According to valence, emotions can be divided into positive and negative. Negative emotion is an emotion generated by external or internal influences in a specific behavior, which is not conducive to the continuous completion of work or normal thinking. It is often accompanied by anxiety, restlessness, anger, disgust, fear and other manifestations [35]. Positive emotions are positive emotions or emotions with positive valence, which is a temporary pleasure. Emotion is one of the factors affecting individual behavior, and negative emotion is often associated with avoidance motivation, so as to avoid actions and avoid punishment. The positive emotion is related to the proactive motivation to obtain greater benefits through active behavior. Studies have shown that positive emotions are associated with the satisfaction of certain needs, usually accompanied by pleasant subjective experience, and can improve people's enthusiasm and activity $[36,37]$. Therefore, this study concludes that individual emotional response plays a mediating role between job insecurity and employee engagement.

First of all, positive and negative emotions are important emotional variables with which to predict individual behavior and are closely related to employee engagement. Based on the cognitive behavior theory, individual emotional state can affect individual behavioral tendency, especially negative emotions, such as fear, anxiety and restlessness, which are prone to generate negative behaviors [38]. In the context of the workplace, negative emotions are usually closely related to specific behaviors. When employees experience unpleasant negative emotions, it is not surprising that they have deviant behaviors [38]. In addition, based on the mood consensus theory, some studies believe that when employees are in a negative mood, they are more likely to pay attention to negative information in thinking, thus affecting their behavioral decisions [39]. Relevant studies have also shown that negative emotions can cause individual job burnout, generate resistance and reduce job participation [40]. Likewise, the study pointed out that there is a close relationship with interpersonal and happiness mood. Individuals with positive emotions have a higher sense of happiness and interpersonal relationships, and are more willing to invest more resources in work, while individuals with negative emotions have lower sense of happiness and interpersonal relationships, and are unwilling to invest more work resources $[15,16]$. Thus, negative emotions had a significantly negative predictive effect on employee engagement, while positive emotions did not. As a positive emotion, positive emotion usually has a positive predictive effect on behavior. Based on the extension-construction theory of positive emotions, some studies have shown that employee engagement originates from the arousal of positive emotions, and positive emotions promote employee engagement by expanding cognitive scope, building psychological resources and activating individual action tendency [41]. Specifically, positive emotions can enhance the individual's cognition of the job, promote employees to rationalize the perception of insecurity and weaken the negative impact on work engagement. In addition, positive emotions are conducive to the improvement of employees' psychological capital and enterprising spirit, promoting employees to be more enthusiastic, work harder and actively participate in work. With emotions as antecedents of behavior, behavior is a reflection of emotional state. Scholars have pointed out that positive emotions can enhance employees' enthusiasm and initiative in work, while negative emotions can hinder employees' initiative and engagement and easily cause employees' deviant behaviors [42].

Secondly, cognitive behavioral theory holds that emotion is the intermediary factor connecting job cognition and employee behavior, that is, employees' cognition of external affairs will trigger emotional response, and then affect their behavior through emotion [20]. On the one hand, the work situation will arouse employees' safety perception, thus causing an emotional response. Scholars point out that when the work situation can make the individual feel a sense of happiness and pride, it can stimulate the individual's positive emotions to a large extent. Conversely, if the work situation causes the individual to lose happiness and pride, it will cause the individual to form negative emotions [43]. Other studies have also shown that work situation factors are closely related to individuals' negative emotions, such as depression, worry and restlessness. Studies have found that employees' assessment of work pressure will affect their emotional state; positive and challenging assessment will lead to positive emotions, 
and obstacle and negative assessment will lead to negative emotions [44]. In addition, based on the theory of self-determination, some researchers found that when an individual's growth or goal realization process is threatened, his or her intrinsic motivation tends to decrease, thus causing negative emotions. However, negative emotions will consume individual resources and thus weaken individual job engagement. On the contrary, when threats are transformed into challenges or opportunities, positive emotions will be enhanced, thus increasing employee engagement [45]. Some research found through interview analysis that when employees face the pressure of job insecurity, they will have evaluation cognition. When evaluation has a positive effect on their career development, they tend to improve their engagement degree, but when evaluation has a negative effect on their development, they are more likely to reduce their investment in work $[13,29]$. Based on the above analysis, this study proposes the following hypotheses:

Hypothesis 2.1. Positive emotion mediates the effect of job insecurity on employee engagement.

Hypothesis 2.2. Negative emotion mediates the effect of job insecurity on employee engagement.

\subsection{The Moderating Effect of Perceived Insider Status}

Perceived insider status is defined as employees' perception of their personal space and acceptance as members of the organization, which focuses on the sense of belonging to the organization [46]. Employees with high level of perceived insider status tend to put the collective interests first and are willing to sacrifice individual interests to realize the long-term development of the organization. They are usually able to show positive attitudes and behaviors, that is, the degree of perceived insider status has a positive impact on the performance of the organization and individual.

There are three reasons for the moderating effect of perceived insider status on the relationship between job insecurity and emotional response. First, perceived insider status and psychological resources. The study points out that employees with perceived insider status have more psychological resources [47] and are more likely to get support from leadership resources [48]. When experiencing job insecurity in the workplace, employees with high perceived insider status usually have enough resources to quickly get out of negative emotions or enhance their original positive emotions without affecting their work. On the other hand, based on the cognitive behavioral theory, in order to maintain insider identity and protect acquired resources, employees with high perceived insider status are more likely to show positive resource-increment behaviors [47,49]. Secondly, the relationship between perceived insider status and loyalty: employees with high perceived insider status have more willingness to safeguard the interests of the organization [50]. Previous studies have shown that the stronger the employee's perceived insider status, the closer the relationship between organizational interests and self-interest, and the more likely it is for employees to show positive attitudes and behaviors [51]. According to this logic, when employees view themselves as the organization's internal person, they will have strong loyalty and sense of belonging to an organization, and are more willing to take responsibility and make efforts; when employees experience the job insecurity, even if the source is a kind of pressure, they will also show more positive emotions, weakening their negative emotions. Third, the relationship between perceived insider status and security. The stronger the perceived insider status is, the more they will show a high sense of trust and obedience to the organization, which will make employees more optimistic about their own work and reduce the anxiety caused by job insecurity [48]. Based on the above analysis, these hypotheses are proposed in this study.

Hypothesis 3.1. Perceived insider status moderates the negative effect of job insecurity on positive emotion.

Hypothesis 3.2. Perceived insider status moderates the positive effect of job insecurity on negative emotion.

Altogether, we summarize our research variables and hypotheses in a conceptual framework in Figure 1. 


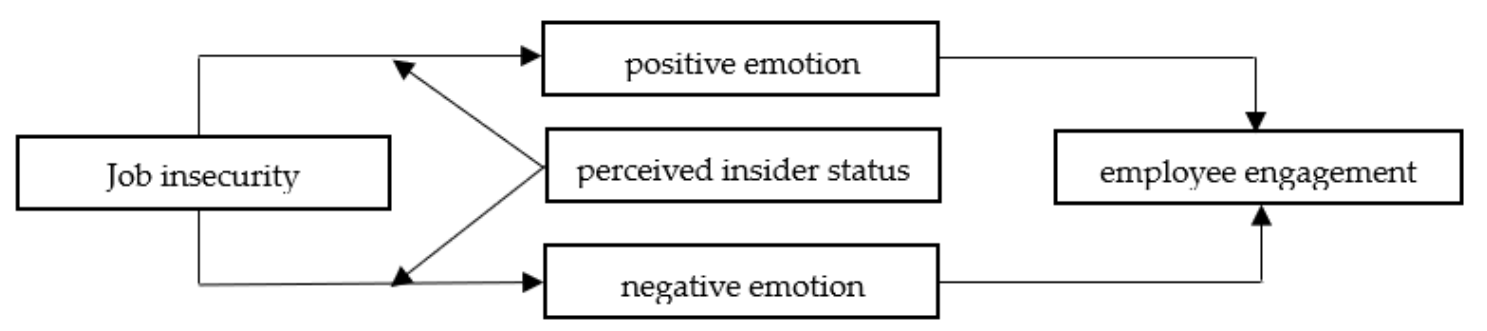

Figure 1. The research conceptual model.

\section{Methodology}

\subsection{Sample and Procedure}

Before the formal investigation, the reliability and validity of the questionnaire was tested via a small-scale pre-survey. The preliminary survey was carried out in March 2020. A total of 50 questionnaires were issued, 44 were recovered, and 42 were valid. A Cronbach's alpha and principal component analysis were used to verify the reliability and validity of the scale. The test results show that the Cronbach's alpha of the five variables were all greater than 0.7. The factor loading values were all greater than 0.5 , thus indicating that the scale has good consistency and reliability. The formal survey involved collecting data by issuing paper questionnaires. The sample data came from employees of four financial institutions in Hunan Province. The survey was conducted in two stages, and each stage was one month apart. The details are as follows: job insecurity, positive emotion, negative emotion, perceived insider status and control variables were investigated for the first phase in April 2020. After an interval of one month, the employee engagement was investigated in May 2020. The specific situation with regard to the questionnaires is as follows: the first time, 385 questionnaires were issued, and 366 valid questionnaires were recovered, with an effective recovery rate of $95.06 \%$. In the second time, 348 questionnaires were recovered, with an effective recovery rate of $95.08 \%$. After matching the two questionnaires, 341 valid questionnaires were finally obtained, with a total effective recovery rate of $88.57 \%$. The sample features are as follows: females represent the majority, accounting for $58.12 \%$. Most employees are within the 31-40 age range or under, with employees under 30 accounting for $32.55 \%$. Employees aged $31-40$ make up $44.57 \%$ of the sample. A total of $16.13 \%$ were aged $41-50$, and $6.75 \%$ were over 50 . In terms of marriage status and children, the largest proportion of respondents were married. In total, $42.22 \%$ were unmarried, and $1.47 \%$ were divorced. In terms of educational background, $7.33 \%$ have a college degree, those with a bachelor's degree account for $66.86 \%$, and those with master's degrees account for $25.81 \%$. From the perspective of posts, front-line employees account for $77.71 \%$ of the respondents, grassroots cadres account for $15.54 \%$, and middle-level cadres account for $6.75 \%$.

\subsection{Measurements}

The scales used in this study are all mature scales applied in a Chinese context. In order to ensure the reliability and validity of the research results, human resources experts with good English skills were invited to examine and translate the scale before the questionnaire was sent out. This was done to ensure the accuracy of the expression. A Likert's 5-point scoring method was adopted in the questionnaire, where 1 means "very inconsistent" and 5 means "very consistent".

The job insecurity scale. Using the 7-item scale compiled by Hellgren et al. [52], typical statements in the scale included "I am worried that I will be fired in the future" and "I feel uneasy that I may lose my job in the future". The reliability and validity of the scale have been verified by domestic studies. In this part of the study, the Cronbach's $\alpha=0.938$.

Emotional scale. The scale is divided into positive emotions and negative emotions. The two-dimensional 12-item emotion scale developed by Warr et al. is used [53]. Typical items for negative emotions are such as "My work makes me angry", and typical items for positive emotions are 
such as "At work. In, I feel objective" and so on. In this study, the negative emotion scale's Cronbach's $\alpha=0.778$, and the positive emotion scale's Cronbach's $\alpha=0.644$.

Perceived insider status Scale. Using the 6-item scale compiled by Stamper and Masterson [46], typical items such as "My work organization makes a sense of belonging" and so on. The Cronbach's $\alpha=0.920$.

Employee engagement scale. Using the 9-item condensed scale developed by Schaufeli et al. [54], typical items of the scale are "I am always motivated at work". In this study, the scale's Cronbach's $\alpha=0.939$.

Control variables. Based on a review of existing literature, this paper finds that demographic information and other relevant factors (gender, age, education, marriage and position) can affect the dependent variables. Therefore, these factors were controlled during the analysis.

\subsection{Descriptive Statistics and Correlation Analysis}

Table 1 shows the descriptive statistics and correlations among all variables.

Table 1. Descriptive statistical results and correlation coefficients.

\begin{tabular}{ccccccc}
\hline Variable & Mean & SD & $\mathbf{1}$ & $\mathbf{2}$ & $\mathbf{3}$ & $\mathbf{4}$ \\
\hline Job insecurity & 2.457 & 0.891 & & & & \\
negative emotions & 2.630 & 0.729 & $0.661^{* *}$ & & & \\
positive emotions & 2.212 & 0.668 & $-0.273^{* *}$ & -0.081 & & \\
Perceived insider status & 2.792 & 0.934 & $-0.223^{* *}$ & $-0.215^{* *}$ & $0.332 * *$ & \\
employee engagement & 3.166 & 0.994 & $-0.418^{* *}$ & $-0.360^{*}$ & $0.292^{* *}$ & $0.274^{* *}$ \\
\hline
\end{tabular}

Note: ${ }^{* *}$ and ${ }^{*}$, respectively, represent $p<0.01$ and $p<0.05$. The same as below.

\section{Preliminary Analyses and Results}

\subsection{Common Method Deviation Test}

Following Zhou and Long's suggestions, we first conducted a varimax rotation analysis of principal factors for all variables to examine the presence and magnitude of the common method variance, according to the number of factor precipitation or common factor interpretation. Five common factors (Eigen value $>1$ ) were extracted from the test results, and the first factor explained only $30.00 \%$ of the variance, that is, less than the recommended explanation criterion of $50 \%$. Therefore, we reasonably concluded that the common method variance in the present research was not significant.

\subsection{Confirmatory Factor Analysis}

Before testing the hypotheses, we examined the distinctiveness of the research variables. We conducted confirmatory factor analyses (CFA) with maximum likelihood estimation in Amos. The CFA results in Table 2 demonstrate that our hypothesized five-factor model (i.e., job insecurity, positive emotions, negative emotions, perceived insider status, employee engagement) was a better fit to the data $\left(\chi^{2}=1086.57, \mathrm{df}=517, \mathrm{RMSEA}=0.059, \mathrm{CFI}=0.920, \mathrm{NFI}=0.906, \mathrm{TFI}=0.913\right)$ than these more parsimonious models. All five-factor models meet the requirements of confirmatory factor indicators, indicating that the research has good discriminative validity. 
Table 2. Confirmatory Factor Analysis.

\begin{tabular}{lcccccc}
\hline \multicolumn{1}{c}{ Variable } & $\chi^{\mathbf{2}}$ & df & RMSEA & CFI & NFI & TLI \\
\hline Five-factor model (JI, NE, PE, EE, PS) & 1086.57 & 517 & 0.059 & 0.920 & 0.906 & 0.913 \\
Four-factor model (JI, NE + PE, EE, PS) & 1398.11 & 521 & 0.071 & 0.877 & 0.818 & 0.867 \\
Three-factor model (JI, NE + PE + PS, EE) & 1814.95 & 524 & 0.088 & 0.819 & 0.764 & 0.806 \\
Two-factor model (JI + NE + PE + PS, EE) & 2594.62 & 526 & 0.112 & 0.709 & 0.662 & 0.690 \\
Single factor model (JI + NE + PE + PS + EE) & 4198.63 & 527 & 0.149 & 0.484 & 0.453 & 0.451 \\
\hline
\end{tabular}

Note: Job insecurity $=\mathrm{JI}$, negative emotion $=\mathrm{NE}$, positive emotion $=\mathrm{PE}$, employee engagement $=\mathrm{EE}$, perceived insider status $=$ PS.

\subsection{Hypothesis Testing}

In order to test the influence relationship among variables, a regression analysis on the data was conducted. The results are shown in Table 3. As can be seen from the data results of Model 2, the impact of job insecurity on employee engagement reaches a significant level ( $\beta=-0.455, p<0.001)$, indicating that job insecurity has a significant negative impact on employee engagement. Therefore, Hypothesis 1 is verified. According to the data analysis results of Model 6, job insecurity has a significant positive impact on negative emotions $(\beta=0.567, p<0.001)$, and has a significant negative impact on positive emotions $(\beta=-0.199, p<0.001)$.

Table 3. Hierarchical regression analysis results of direct effects.

\begin{tabular}{ccccccc}
\hline \multirow{2}{*}{ Variable } & \multicolumn{2}{c}{ Employee Engagement } & \multicolumn{2}{c}{ Negative Emotions } & \multicolumn{2}{c}{ Positive Emotions } \\
\cline { 2 - 6 } & M1 & M2 & M3 & M4 & M5 & M6 \\
\hline Sex & -0.047 & -0.046 & -0.042 & -0.043 & -0.022 & -0.018 \\
\hline Age & $-0.148^{*}$ & -0.124 & 0.024 & 0.008 & $0.090^{*}$ & $0.098^{*}$ \\
\hline Position & -0.040 & -0.025 & -0.028 & -0.048 & -0.072 & -0.065 \\
\hline Education & 0.067 & 0.063 & 0.043 & 0.048 & 0.064 & 0.067 \\
\hline Job Insecurity & & $-0.455^{* * *}$ & & $0.567^{* * *}$ & & $-0.199^{* * *}$ \\
\hline $\mathrm{F}$ & 2.130 & $13.308^{* * *}$ & 0.473 & $50.145^{* * *}$ & 2.229 & $6.864^{* * *}$ \\
\hline $\mathrm{R}^{2}$ & 0.031 & 0.193 & 0.008 & 0.474 & 0.032 & 0.110 \\
\hline$\Delta \mathrm{R}^{2}$ & 0.017 & 0.178 & 0.007 & 0.464 & 0.018 & 0.094 \\
\hline
\end{tabular}

The mediating effect of emotions is tested based on the three-step method of mediating. (1) This is done to test whether the independent variable job insecurity has a significant influence on the dependent variable's employee engagement. From Table 4 Model 2, it can be seen that job insecurity has a significant negative influence on employee engagement $(\beta=-0.455, p<0.01)$. (2) Test whether the independent variable job insecurity has a significant effect on the mediating variable positive emotion and negative emotions. As can be seen from Table 3 Model 6, job insecurity has a significant negative effect on positive emotions $(\beta=-0.199, p<0.001)$, has a positive effect on negative emotion (Table 3 Model $4, \beta=0.567, p<0.001$ ). (3) Regress the dependent variable employee engagement on the independent variable work insecurity and the mediating variable negative and positive emotions, As shown in Table 4, negative emotions have a significant impact on engagement (Model 6, $\beta=-0.189$, $p<0.05)$, While job insecurity has a significant impact on employee engagement, compared to Model 2 , the coefficient of work insecurity becomes smaller. Explain that negative emotions play a part of the mediating role between job insecurity and employee engagement. This conclusion supports the Hypothesis 2.2. Similarly, as shown in Table 4 and Model 5, positive emotions have significant effects on employee engagement (Model $5, \beta=0.327, p<0.001$ ). However, compared with Model 2 , the significant coefficient of work insecurity is reduced $(\beta=-0.390, p<0.001)$, indicating that 
positive emotions play a part of the mediating role between work insecurity and employee engagement. Hypothesis 2.1 has been verified.

Table 4. Hierarchical regression analysis results of mediating effects.

\begin{tabular}{ccccccc}
\hline \multirow{2}{*}{ Variable } & \multicolumn{7}{c}{ Employee Engagement } \\
\cline { 2 - 7 } & M1 & M2 & M3 & M4 & M5 & M6 \\
\hline Sex & -0.050 & -0.059 & -0.060 & -0.087 & -0.064 & -0.073 \\
\hline Age & $-0.142^{*}$ & -0.124 & $-0.184^{* *}$ & -0.122 & $-0.154^{*}$ & -0.120 \\
\hline Position & -0.049 & -0.033 & -0.016 & -0.067 & -0.013 & -0.045 \\
\hline Education & 0.063 & 0.070 & 0.033 & 0.098 & 0.049 & 0.084 \\
\hline Job Insecurity & & $-0.455^{* * *}$ & & $-0.390^{* * *}$ & $-0.348^{* * *}$ \\
\hline Positive Emotions & & & $0.484^{* * *}$ & & $0.327^{* * *}$ & \\
\hline Negative Emotions & & & $-0.477^{* * *}$ & & $-0.189^{*}$ \\
\hline $\mathrm{F}$ & 1.746 & $12.396^{* * *}$ & $6.651^{* * *}$ & $9.680^{* * *}$ & $13.090^{* * *}$ & $11.606^{* * * *}$ \\
\hline $\mathrm{R}^{2}$ & 0.027 & 0.194 & 0.114 & 0.158 & 0.229 & 0.209 \\
\hline$\Delta \mathrm{R}^{2}$ & 0.012 & 0.178 & 0.097 & 0.142 & 0.212 & 0.191 \\
\hline
\end{tabular}

Note: ${ }^{* * *},{ }^{* *}$ and ${ }^{*}$, respectively, represent $p<0.001, p<0.01$ and $p<0.05$

The interaction term between job insecurity and perceived insider status (job insecurity $\times$ perceived insider status) was put into the regression equation, in order to test the moderating effect of perceived insider status (see Table 5). The results show that the interaction term has a significant negative impact on positive emotions (Model $4, \beta=-0.102, p<0.01$ ). It can be seen from this that the perceived insider status has a negative moderating effect between work insecurity and positive emotion. Hypothesis 3.1 is thus supported. Similarly, the perceived insider status has a moderating effect between work insecurity and negative emotions. As shown in Table 5, the interaction item has a significant negative impact on negative emotions. As shown in Table 5 , the interaction item has a significant negative impact on negative emotions (Model $8, \beta=-0.074, p<0.05$ ). It can be concluded that employees' internal identity perception also plays a moderating role between job insecurity and negative emotions. Hypothesis 3.2 is supported.

Table 5. Results of hierarchical regression analysis of simple regulatory effects.

\begin{tabular}{|c|c|c|c|c|c|c|c|c|}
\hline \multirow{2}{*}{ Variable } & \multicolumn{4}{|c|}{ Positive Emotions } & \multicolumn{4}{|c|}{ Negative Emotions } \\
\hline & M1 & M2 & M3 & M4 & M5 & M6 & M7 & M8 \\
\hline Sex & -0.050 & -0.059 & 0.001 & -0.006 & -0.042 & -0.043 & -0.039 & -0.044 \\
\hline Age & $-0.142 *$ & -0.124 & 0.084 * & 0.082 & 0.024 & 0.008 & 0.011 & 0.011 \\
\hline Position & -0.049 & -0.033 & -0.010 & -0.007 & -0.028 & -0.048 & -0.064 & -0.062 \\
\hline Education & 0.063 & 0.070 & 0.045 & 0.041 & 0.043 & 0.048 & 0.054 & 0.051 \\
\hline Job Insecurity & & $-0.460 * * *$ & $-0.163^{* * *}$ & 0.112 & & $0.567^{* * *}$ & $0.557^{* * *}$ & $0.556^{* * *}$ \\
\hline Perceived Insider Status & & & $0.188^{* * *}$ & $0.431^{* * *}$ & & & -0.054 & 0.122 \\
\hline $\begin{array}{c}\text { Job Insecurity } \times \text { Perceived } \\
\text { Insider Status }\end{array}$ & & & & $-0.102 * *$ & & & & -0.074 * \\
\hline $\mathrm{F}$ & 1.746 & $12.396^{* * *}$ & $9.159^{* * *}$ & $8.970 * * *$ & 0.473 & $50.145^{* * *}$ & 43.564 & 38.995 \\
\hline $\mathrm{R}^{2}$ & 0.027 & 0.194 & 0.172 & 0.189 & 0.008 & 0.474 & 0.478 & 0.484 \\
\hline$\Delta \mathrm{R}^{2}$ & 0.012 & 0.178 & 0.153 & 0.168 & 0.007 & 0.464 & 0.467 & 0.472 \\
\hline
\end{tabular}

In order to more vividly express and illustrate the moderating effect of Perceived insider status, this study drew a pitch diagram of the relationship between job insecurity and employees' negative 
emotions/positive emotions. The diagram is based on the drawing method and procedure proposed by Aiken et al. [55] (see Figures 2 and 3). As can also be seen from Figure 2, perceived insider status does not change the negative relationship between job insecurity and positive emotions. However, perceived insider status can moderate their relationship. Relatively low perceived insider status (M - 1SD) of employees and high perceived insider status $(M+1 S D)$ of employees can alleviate the negative effect of work insecurity on positive emotions, Hypothesis 3.1 is further supported. The same perceived insider status exerts a negative moderating effect between work insecurity and negative emotions, as shown in Figure 3, and a relatively low perceived insider status (M - 1SD), high perceived insider status $(M+1 S D)$ can weaken the positive impact of work insecurity on negative emotions. Therefore, Hypothesis 3.2 is further supported.

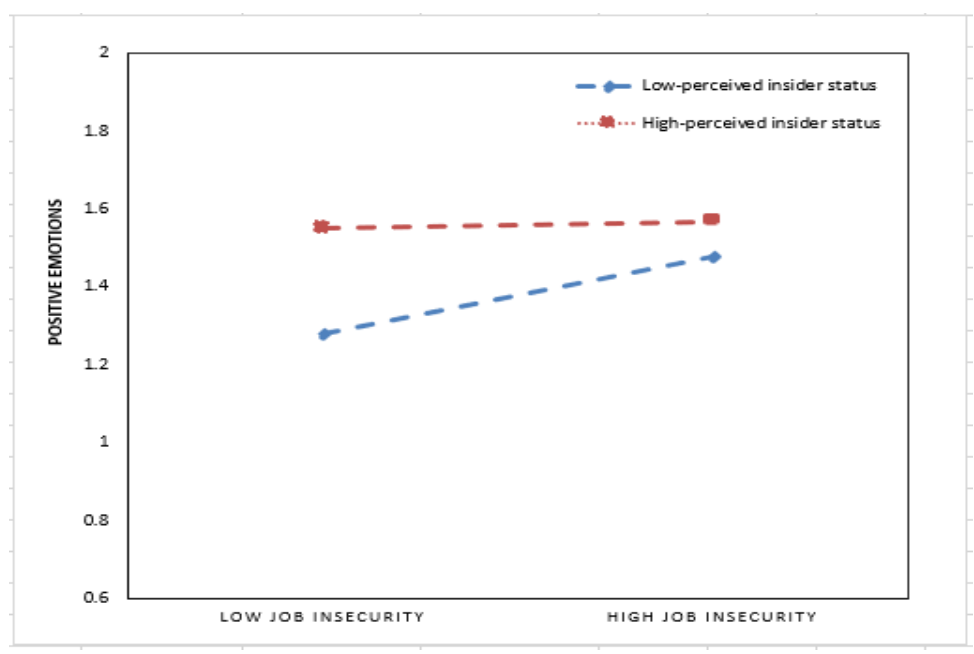

Figure 2. Moderating effect of perceived insider status between job insecurity and positive emotion.

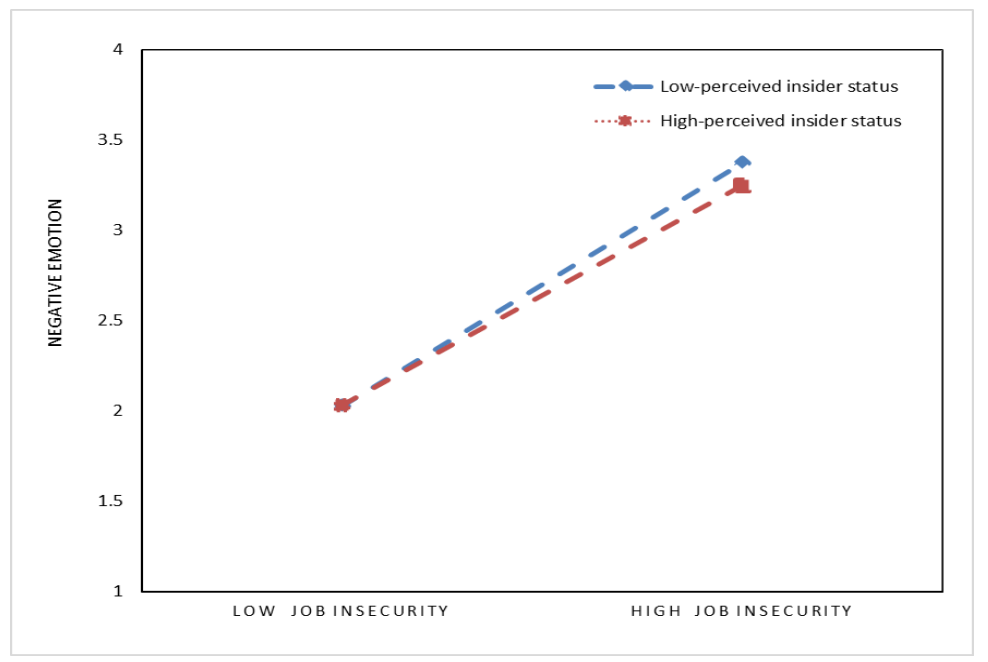

Figure 3. Moderating effect of perceived insider status between job insecurity and negative emotion.

\section{Discussion and Conclusions}

\subsection{Conclusions}

This study draws the following conclusions: There is a significant negative impact of job insecurity and employee engagement; positive emotions and negative emotions play a mediated role between job insecurity and employee engagement. Job insecurity has a negative impact on employee engagement by positively affecting positive emotions, and has a negative impact on employee engagement by 
positively affecting negative emotions. Perceived insider status plays a moderated role between job insecurity and positive emotion, and also moderated the relationship between job insecurity and negative emotion.

\subsection{Theoretical Contribution}

This study mainly has the following theoretical contributions: (1) Discussing the relationship between job insecurity and employee engagement. A review of previous studies found that the effect of work insecurity has been controversial. For example, job insecurity has a negative impact on job engagement and happiness [3,18], and a positive impact on creativity and initiative $[19,20]$. Therefore, the impact of job insecurity should be analyzed on a case-by-case basis. This study finds that job insecurity has a significant negative impact on employee engagement, which is consistent with the research results of Feng et al. [10] and Jung et al. [26]. (2) Systematically exploring the role of job insecurity on employee engagement path. Based on cognitive behavioral theory, this study found that positive emotions and negative emotions play a part in the mediating role between job insecurity and employee engagement. Previous studies on job insecurity mainly started from the perspectives of cognition and motivation $[10,26]$, while this study, from the perspective of emotion, reveal the role of job insecurity through emotions. On the other hand, the cognitive behavioral evaluation theory is proved again in the Context of China, namely, emotion is the bridge connecting the perception of work situation and employee behavior [20]. More importantly, no research has yet integrated job insecurity, positive emotion, negative emotion and employee engagement. This study proposes and verifies the mediating effect of job insecurity through emotions on employee engagement, and theoretically verifies the relationship between the four. In addition, this conclusion also proves the judgment of Zhu Han et al. [17], that is, employee behavior is not only the result of operation management, but also the result of emotion. This study breaks through the single limitation that job insecurity affects employee engagement and investigates the double-path effect of job insecurity on employee engagement. (3) The boundary conditions of job insecurity on employees' emotions were systematically discussed. This study finds that perceived insider status negatively moderated the relationship between job security and emotion. On the one hand, this conclusion verifies that employee emotions are the result of the interaction between individual factors and situational factors. On the other hand, it reveals the reasons for the differences in employees' emotions under the same situation. For employees with high perceived insider status, it can weaken the negative effect of work insecurity on employees' positive emotions, and it can also weaken the positive effect of work insecurity on employees' negative emotions, because high perceived insider status implies individual tendencies to safeguard the interests of the organization, while individuals with a low perceived insider status tend to safeguard their own interests. The research conclusion further supports the positive effect of insider identity perception, that is, the stronger the internal identity perception, the more positive behavior choices there will be, and conversely, the more negative [14,35]. The research results expand the theoretical perspective of the relationship between job insecurity and employee engagement.

\subsection{Management Implications}

From the perspective of job insecurity, this study explores the process of emotional impact on engagement, providing a more comprehensive theoretical basis for organizations to understand job insecurity [20]. Cognitive behavioral theory not only provides a new perspective for the study, but also provides an operational method to intervene in job insecurity in the workplace: (1) the study found that job insecurity has negative effect on employee engagement, the prompt manager can, through creating a stable, reliable, and safe working environment, reduce the employee insecurity awareness, such as improving employees work skills through training, enhancing its hiring sex, and implementing a management system for matching people and positions to improve employee job satisfaction. Reducing work performance standards and improving employee protection systems, etc., reduces the negative impact of work insecurity and even eliminates the source of insecurity. At the same time, 
in the process of organizing human resource management, pay attention to the index evaluation of occupational insecurity, such as the elimination of personnel with low psychological bearing ability in the recruitment process, and attention should be paid to the training of psychological bearing ability in daily training, so as to ensure the sustainability of the human resource system. (2) The study found that emotions play a mediating role, which suggests that managers should continue to pay attention to employees' emotional reactions, especially negative emotions, and do a good job in calming employees' emotions. To be specific, we should pay attention to the creation of a positive emotional atmosphere, the formation of a fearless and positive organizational spirit, and guide employees toward the direction conducive to organizational goals. The organization needs to set up special emotional counseling personnel and offices to timely do a good job of emotional counseling. When employees are worried and nervous about losing their jobs, the organization should provide more emotional support such as communication and care, focus on improve their emotional commitment. In addition, employees' insecurity caused by environmental instability can be weakened by improving their remuneration, such as increasing welfare and salary, holidays and rest time, etc., which can alleviate their negative emotional reactions to a certain extent. (3) The study confirms that perceived insider status has a moderating effect between job insecurity and emotion, and whether it can alleviate the impact of job insecurity on negative emotion. Managers can increase employees' perceived insider status through material and spiritual aspects. For example, they can give employees more autonomy in their work, implement family-friendly welfare policies, pay attention to employees' family life, and improve their sense of belonging. In addition, the management should pay attention to fairness, build a fair and transparent promotion mechanism with clear rewards and punishments, give certain commendations to employees as often as possible, and promote an inclusive working atmosphere.

\subsection{Research Limitations and Future Prospects}

The conclusions of this research support some hypotheses, but there are still some limitations in data, theory, variables and other aspects of the study. (1) Single data source. Although the sample data were collected from two time periods, only a self-reported measurement method was adopted. Although this method was scientifically reasonable, it lacked mutual verification from multiple perspectives. Future research may consider adding other methods to improve the credibility of the data. (2) Variable selection is unitary. Although this study examines the perceived insider status as a moderator variable between job insecurity and employee emotion, there are still many factors that influence the process of action, such as organizational level, team level, family level, etc. Future studies may further explore the impact of other boundary variables. In addition, the study only considers emotion as a mediating variable, but in fact, individual perception, evaluation and other factors may play a role in the whole process. Therefore, the research on mediating variables was expanded to improve the Nomo network in the later period. (3) The research content needs to be expanded. In this study, job insecurity was taken as an independent variable, but as a perception variable, the field of antecedent variables remained to be further analyzed. In the follow-up studies, the influencing factors of job insecurity could be discussed to build a complete chain mediation framework.

Author Contributions: S.Y. designed the research framework and wrote the paper, analyzed the data. X.G. and N.W. edited the paper. All authors have read and agreed to the published version of the manuscript.

Funding: This research has been supported by the Fundamental Research Funds for the Natural Science Foundation of China (Grant no. 71832003, and 71672056).

Acknowledgments: The authors are grateful to all the funding agencies, the editors, and the anonymous referees for valuable comments and suggestions.

Conflicts of Interest: The authors declare no conflict of interest. 


\section{References}

1. Greenhalgh, L.; Rosenblatt, Z. Job Insecurity: Toward Conceptual Clarity. Acad. Manag. Rev. 1984, 9, 438-448. [CrossRef]

2. Witte, H.D. Job Insecurity and Psychological Well-being: Review of the Literature and Exploration of Some Unresolved Issues. Eur. J. Work Organ. Psychol. 1999, 8, 155-177. [CrossRef]

3. Sverke, M.; Hellgren, J.N.; Näswall, K. No security: A meta-analysis and review of job insecurity and its consequences. J. Occup. Health Psychol. 2002, 73, 242-264. [CrossRef]

4. Breevaart, K.; Bohle, S.L.; Pletzer, J.L.; Medina, F.M. Voice and silence as immediate consequences of job insecurity. Career Dev. Int. 2020, 25, 204-220. [CrossRef]

5. Baillien, E.; Witte, H.D. Why is Organizational Change Related to Workplace Bullying? Role Conflict and Job Insecurity as Mediators. Econ. Ind. Democr. 2009, 30, 348-371. [CrossRef]

6. Kim, M.-J.; Kim, B.-J. Analysis of the Importance of Job Insecurity, Psychological Safety and Job Satisfaction in the CSR-Performance Link. Sustainability 2020, 12, 3514. [CrossRef]

7. Hu, S.M.; Zhong, H. Relationship between Job Insecurity and Job Well-being: Moderating Effect of Perceived Employability. J. Clin. Psychol. 2015, 23, 321-325. [CrossRef]

8. Babel'ová, Z.; Stareček, A.; Cagáňová, D.; Fero, M.; Čambál, M. Perceived Serviceability of Outplacement Programs as a Part of Sustainable Human Resource Management. Sustainability 2019, 11, 4748. [CrossRef]

9. Bal, P.M.; Kooij, D.T.A.M.; De Jong, S.B. How Do Developmental and Accommodative HRM Enhance Employee Engagement and Commitment? The Role of Psychological Contract and SOC Strategies. J. Manag. Stud. 2013, 50, 545-572. [CrossRef]

10. Yan, Y.L.; Zhang, J.W.; Zhang, H. A Study on the Relationship between Positive leadership and Employee Engagement: From the perspective of Self-determination. J. Clin. Psychol. 2018, 12, 102-119.

11. Rich, B.L.; Lepine, J.A.; Crawford, E.R. Job Engagement: Antecedents and Effects on Job Performance. Acad. Manag. J. 2010, 53, 617-635. [CrossRef]

12. Bakker, A.B.; Schaufeli, W.B. Positive organizational behavior: Engaged employees in flourishing organizations. J. Organ. Behav. 2008, 29, 147-154. [CrossRef]

13. Jena, L.K.; Pradhan, S.; Panigrahy, N.P. Pursuit of organisational trust: Role of employee engagement, psychological well-being and transformational leadership. Asia Pac. Manag. Rev. 2018, 23, 227-234. [CrossRef]

14. Asfaw, A.G.; Chang, C.-C. The association between job insecurity and engagement of employees at work. J. Work. Behav. Health 2019, 34, 96-110. [CrossRef] [PubMed]

15. Yang, L.-Q.; Zheng, X.; Liu, X.; Lu, C.-Q.; Schaubroeck, J.M. Abusive supervision, thwarted belongingness, and workplace safety: A group engagement perspective. J. Appl. Psychol. 2020, 105, 230-244. [CrossRef]

16. Feng, W.D. A Study the Relationship among Job Insecurity, Employee Engagement and Job Performance of Teachers in Universities and Colleges under the Background of Appointive Employment System. Ph.D. Thesis, Southwestern University of Finance and Economics, Chengdu, China, 2014.

17. Zhu, H. The practice of ABC theory of rational emotion in employee conflict management. Ind. Sci. Trib. 2013, 22, 99-100.

18. Gross, J.J.; John, O.P. Individual differences in two emotion regulation processes: Implications for affect, relationships, and well-being. J. Pers. Soc. Psychol. 2003, 85, 348-362. [CrossRef]

19. Yin, H.; Huang, S.; Lv, L. A Multilevel Analysis of Job Characteristics, Emotion Regulation, and Teacher Well-Being: A Job Demands-Resources Model. Front. Psychol. 2018, 9, 2395. [CrossRef]

20. Jeong, D.Y.; Kim, C.; Chang, S.-J. Emotional Labor and Burnout: A Review of the Literature. Yonsei Med. J. 2018, 59, 187-193. [CrossRef]

21. Chen, Z.X.; Aryee, S. Delegation and Employee Work Outcomes: An Examination of the Cultural Context of Mediating Processes in China. Acad. Manag. J. 2007, 50, 226-238. [CrossRef]

22. Wang, H.; Lee, C.; Hui, C. I want to be included: Sources of perceived insider status and why insider status is important. Presented at the Asia Academy of Management Conference, Tokyo, Japan, 19-21 December 2006.

23. De Cuyper, N.; De Witte, H. The impact of job insecurity and contract type on attitudes, well-being and behavioural reports: A psychological contract perspective. J. Occup. Organ. Psychol. 2006, 79, 395-409. [CrossRef] 
24. Zhou, H.; Rong, L.R. The impact of job insecurity and creative self-efficacy on employee creativity. J. Psychol. 2011, 8, 929-940.

25. Jung, H.S.; Jung, Y.S.; Yoon, H.H. COVID-19: The effects of job insecurity on the job engagement and turnover intent of deluxe hotel employees and the moderating role of generational characteristics-ScienceDirect. Int. J. Hosp. Manag. 2020, 92, 1027. [CrossRef] [PubMed]

26. Wong, Y.-T.; Wong, C.-S.; Ngo, H.-Y.; Lui, H.-K. Different responses to job insecurity of Chinese workers in joint ventures and state-owned enterprises. Hum. Relat. 2005, 58, 1391-1418. [CrossRef]

27. Cavanaugh, M.A.; Boswell, W.R.; Roehling, M.V.; Boudreau, J.W. An empirical examination of self-reported work stress among U.S. managers. J. Appl. Psychol. 2000, 85, 65-74. [CrossRef]

28. Zhang, G.P.; Liao, J.Q. Study on the influence mechanism of challenge-blocking pressure on employee engagement. Sci. Res. Manag. 2015, 36, 152-159.

29. Wang, H.L.; Zhang, Q.J. The cost of trust: A study on the relationship between employees' perception of superior trust, role load, work pressure and emotional exhaustion. Manag. World 2016, 8, 110-125. [CrossRef]

30. Dawson, K.M.; O'Brien, K.E.; Beehr, T.A. The role of hindrance stressors in the job demand-control-support model of occupational stress: A proposed theory revision. J. Organ. Behav. 2016, 37, 397-415. [CrossRef]

31. Aselage, J.; Eisenberger, R. Perceived organizational support and psychological contracts: A theoretical integration. J. Organ. Behav. 2003, 24, 491-509. [CrossRef]

32. Greenhalgh, L.; Rosenblatt, Z. Evolution of Research on Job Insecurity. Int. Stud. Manag. Organ. 2010, 40, 6-19. [CrossRef]

33. Saks, A.M. Antecedents and consequences of employee engagement. J. Manag. Psychol. 2006, 21, 600-619. [CrossRef]

34. Kahn, W.A. Psychological conditions of personal engagement and disengagement at work. Acad. Manag. J. 1990, 33, 692-724.

35. Brief, A.P.; Weiss, H.M. Organizational Behavior: Affect in the Workplace. Annu. Rev. Psychol. 2002, 53, 279-307. [CrossRef] [PubMed]

36. Talarico, J.M.; Berntsen, D.; Rubin, D.C. Positive emotions enhance recall of peripheral details. Cogn. Emot. 2009, 23, 380-398. [CrossRef]

37. Lazarus, R.S. Emotion and Adaption; Oxford University Press: New York, NY, USA, 1991.

38. Guo, X.Y.; Wang, Z.H. The conception, power and meaning of the mood. J. Psychol. Sci. 2007, 15, 810-815.

39. Wei, W.; Huang, C.Y.; Zhang, Q. The influence of negative emotion on organizational citizenship behavior and counterproductive Work Behavior: Self-control perspective. Manag. Rev. 2019, 31, 146-158.

40. Thoresen, C.J.; Kaplan, S.A.; Barsky, A.P.; Warren, C.R.; De Chermont, K. The Affective Underpinnings of Job Perceptions and Attitudes: A Meta-Analytic Review and Integration. Psychol. Bull. 2003, 129, 914-945. [CrossRef]

41. Harley, J.M.; Lajoie, S.P.; Tressel, T.; Jarrell, A. Fostering positive emotions and history knowledge with location-based augmented reality and tour-guide prompts. Learn. Instr. 2020, 70, 101163. [CrossRef]

42. Judge, T.A.; Scott, B.A.; Ilies, R. Hostility, job attitudes, and workplace deviance: Test of a multilevel model. J. Appl. Psychol. 2006, 91, 126-138. [CrossRef]

43. Bakker, A.B.; Demerouti, E.; Schaufeli, W.B. Dual processes at work in a call centre: An application of the job demands-resources model. Eur. J. Work Organ. Psychol. 2003, 12, 393-417. [CrossRef]

44. Li, H.; Zhan, L.; Huang, M.; Zhao, X.; Zhou, C.; Qiang, Z. Effects of pre-strain and stress level on stress relaxation ageing behaviour of $2195 \mathrm{Al}-\mathrm{Li}$ alloy: Experimental and constitutive modelling. J. Alloys Compd. 2020, 8, 51. [CrossRef]

45. Gu, J.; Wu, H.; Li, Y.; Hermawan, E.D. Influence of the Mechanism of the Community of Shared Future on the Innovation Performance of Knowledge Workers: The Intermediary Role of Extra-Role Behavior. Sustainability 2019, 11, 5370. [CrossRef]

46. Stamper, C.L.; Masterson, S.S. Insider or outsider? How employee perceptions of insider status affect their work behavior. J. Organ. Behav. 2002, 23, 875-894. [CrossRef]

47. Li, Y.P.; Zheng, X.Y.; Liu, Z.H. Research on the influence mechanism of insider identity perception on employee voice behavior based on resource conservation theory. J. Chin. Manag. 2017, 14, 196-204.

48. Wang, Y.F.; Cai, R.Y.; Lin, X.C. The relationship between the insider identity cognition and the innovation behavior, survey of the media to effect model. Foreign Econ. Manag. 2014, 10, 40-53. 
49. Li, Y.; Sun, J.-M. Traditional Chinese leadership and employee voice behavior: A cross-level examination. Leadersh. Q. 2015, 26, 172-189. [CrossRef]

50. Yin, J.; Wang, H. The influence of empowering leadership behavior on employee's perception of insider identity: The moderating effect of organization-based self-esteem. Acta Psychol. Sin. 2012, 44, 1371-1382.

51. Knapp, J.R.; Smith, B.R.; Sprinkle, T.A. Clarifying the Relational Ties of Organizational Belonging. J. Leadersh. Organ. Stud. 2014, 21, 273-285. [CrossRef]

52. Hellgren, J.; Sverke, M.; Isaksson, K. A Two-dimensional Approach to Job Insecurity: Consequences for Employee Attitudes and Well-being. Eur. J. Work. Organ. Psychol. 1999, 8, 179-195. [CrossRef]

53. Warr, P. The measurement of well-being and other aspects of mental health. J. Occup. Psychol. 1990, 63, 193-210. [CrossRef]

54. Schaufeli, W.B.; Marti, I.M.; Pinto, A.M.; Salanova, M.; Bakker, A.B. Burnout and Engagement in university Students across-National Study. J. Cross Cult. Psychol. 2002, 33, 464-481. [CrossRef]

55. Aiken, L.S.; West, S.G. Multiple Regression: Testing and Interpreting Interactions; Sage Publications Inc.: Newbury Park, CA, USA, 1991.

Publisher's Note: MDPI stays neutral with regard to jurisdictional claims in published maps and institutional affiliations.

(C) 2020 by the authors. Licensee MDPI, Basel, Switzerland. This article is an open access article distributed under the terms and conditions of the Creative Commons Attribution (CC BY) license (http://creativecommons.org/licenses/by/4.0/). 